\section{Saúde mental de adolescentes internados no sistema socioeducativo: relação entre as equipes das unidades e a rede de saúde mental}

\author{
Mental health of adolescents in the juvenile \\ detention system: the relationship between the \\ system's staff and external mental health services
}

\section{Salud mental de adolescentes internados en el sistema de reinserción socioeducativo: relación entre los equipos de las unidades y la red de salud mental}

Débora Stephanie Ribeiro 1

Fernanda Mendes Lages Ribeiro 1

Suely Ferreira Deslandes 1

\title{
Resumo
}

Este artigo tem como objetivo analisar como os profissionais das equipes de saúde mental do sistema socioeducativo do Rio de Janeiro, Brasil, percebem as relações estabelecidas com a Rede de Atenção Psicossocial para atenção às questões de saúde mental dos adolescentes que cumprem medida de internação. Realizaram-se nove entrevistas com profissionais de saúde mental do sistema e os resultados foram apresentados tendo como referência a análise de discurso crítica de Fairclough. Os resultados foram organizados em três partes: relação entre as equipes de saúde mental e a rede, dificuldades das equipes das unidades e dos serviços da rede, e perspectivas e propostas. Pela lógica de construção dos argumentos identificados percebeu-se que a fragilidade dos pactos entre os gestores do Sistema Único de Saúde e do sistema socioeducativo impacta o cotidiano das ações de saúde mental desenvolvidas pelas equipes das unidades. Esse cenário associa-se a outros problemas estruturais, como a falta de transporte e a indisponibilidade de agentes para acompanharem os adolescentes nos atendimentos externos, e às resistências dos profissionais tanto dentro quanto fora das unidades. Evidencia-se haver um isolamento tanto dos adolescentes quanto dos profissionais em relação às ações e politicas de saúde mental do território.

Saúde Mental; Serviços de Saúde Mental; Adolescente Institucionalizado

\author{
Correspondência \\ D. S. Ribeiro \\ Fundação Oswaldo Cruz. \\ Av. Brasil 4036, sala 700, Rio de Janeiro, RJ 21040-361, Brasil. \\ debora.seds@gmail.com \\ 1 Fundação Oswaldo Cruz, Rio de Janeiro, Brasil.
}




\section{Introdução}

A Política Nacional de Atenção Integral à Saúde de Adolescentes em Conflito com a Lei em Regime de Internação e Internação Provisória (PNAISARI) é regulamentada pelo Ministério da Saúde. De acordo com Portaria no 1.082/2014 1, depreende-se o modelo considerado "ideal" para atenção à saúde dos adolescentes: realizado prioritariamente na atenção básica e, se houver equipe de saúde dentro da unidade socioeducativa, a equipe de atenção básica do território de referência se articulará com ela para inserir os adolescentes nas redes de atenção à saúde, de modo complementar.

Em relação à saúde mental, a política propõe que a equipe de atenção básica do território seja acrescida de profissionais de saúde mental em quantidade que variará conforme o total de adolescentes que cumprem medida. Esses profissionais devem ser cadastrados como integrantes da equipe de atenção básica de referência e poderão ou não ser de Núcleos de Apoio à Saúde da Família 1.

Propõe-se que esses profissionais de saúde mental atuem na lógica de matriciamento. O foco não é que eles realizem atendimento individual, ambulatorial ou façam relatórios.

O modelo pressupõe que a instância federativa responsável pela atenção integral à saúde dos adolescentes faça adesão à PNAISARI. Entretanto, essa adesão não é uma realidade na maior parte dos municípios do Rio de Janeiro, Brasil, inclusive na capital, mesmo contando com a maior quantidade de unidades de internação do estado.

No sistema socioeducativo do Rio de Janeiro há equipes de saúde mental nas seis unidades de internação vinculadas ao Departamento Geral de Ações Socioeducativas (Degase). As equipes desempenham ações de atenção à saúde mental, atendimentos individuais, familiares e grupais, além de realizarem o contato com a Rede de Atenção Psicossocial (RAPS) para a pactuação do acesso dos adolescentes à rede.

A RAPS é voltada para "pessoas com sofrimento ou transtorno mental" ou com necessidades relacionadas ao uso de drogas. Os componentes da rede são: atenção básica, atenção psicossocial especializada (Centros de Atenção Psicossocial - CAPS), atenção de urgência e emergência, atenção residencial de caráter transitório, atenção hospitalar, estratégias de desinstitucionalização e reabilitação psicossocial 2.

O CAPS é um dos componentes da RAPS e é constituído como um serviço ambulatorial de atenção diária. O CAPSi, voltado para crianças e adolescentes, tem como funções a assistência direta àqueles com sofrimento psíquico e organização da rede de saúde mental no território, o que inclui supervisão e capacitação das equipes de atenção básica 3. O CAPSad é voltado para aquelas pessoas com necessidades relacionadas ao uso de álcool e outras drogas.

Assim, tendo como referência esses e outros elementos relativos à organização do cuidado e dos serviços de saúde mental infantojuvenis, propõe-se analisar os discursos dos profissionais das equipes de saúde mental das unidades de internação do Degase acerca das relações estabelecidas entre essas equipes e os CAPS, e o impacto nas rotinas do socioeducativo.

\section{Metodologia}

No sistema socioeducativo do Estado do Rio de Janeiro há seis unidades de internação. Os sujeitos da pesquisa foram os profissionais das equipes de saúde mental de duas unidades (uma masculina e outra feminina) e da Coordenação de Saúde Integral e Reinserção Social (CSIRS) do Degase. Foram realizadas nove entrevistas semiestruturadas entre julho e agosto de 2016 com os seguintes profissionais: 4 psicólogos, 2 assistentes sociais, 1 psiquiatra, 1 musicoterapeuta e 1 terapeuta ocupacional. As equipes atuavam em unidades da capital e a rede de CAPSi existente era de sete serviços 4.

Optou-se pela Análise de Discurso Crítica (ADC) para conduzir este trabalho. Segundo Fairclough 5, o discurso evidencia formas de ação e de representação do mundo. Como efeitos do discurso, ele destaca a construção de identidades sociais, das relações sociais e de conhecimento. Ao mesmo tempo em que o discurso influencia a estrutura social, também é influenciado por ela. A ADC foi escolhida como método porque o discurso revela concepções e valores socioculturais que traduzem a realidade de um modo particular, além de ser permeado por concepções ideológicas que reproduzem, justificam ou questionam esta realidade. Os discursos contêm ações sociais implícitas 5. 
Fairclough 5 apresenta uma proposta analítica baseada na concepção tridimensional de discurso. A primeira dimensão é a análise textual e linguística. A segunda é a prática discursiva, em que são analisados os processos de produção textual e o contexto social em que os textos são produzidos e distribuídos. Nessa dimensão analisa-se a coerência do discurso e a ação social decorrente, bem como intertextualidades manifestas e interdiscursividades. Na terceira dimensão o discurso é visto como prática social e propõe-se a análise das relações de poder e das ideologias presentes como formas de construção da realidade.

Os resultados foram organizados didaticamente por temas e em cada um foram ressaltados os elementos textuais que serviram de ponto de partida para a análise de coerência e de coesão. Foram observadas as escolhas da estrutura de argumentação, a racionalidade dos enunciados, além das relações estabelecidas entre as orações.

Destacamos o uso de recursos como modalidade (termos que indicam o grau de assertividade das afirmativas), interdiscursividade, lexicalização de palavras (significados variados de um termo), criação de palavras, nominalização (recursos textuais de transformação de uma condição temporária em uma propriedade; processos em objetos ou coisas), metáforas, uso de negações e de pressuposições, ironia e polidez 5 .

As transcrições das entrevistas gravadas mantiveram a expressão fiel do português falado (sem correções gramaticais), a fim de preservar as nuances semânticas. As entrevistas foram numeradas e reorganizadas por perguntas e temas do roteiro.

Este estudo seguiu todos os preceitos éticos de uma pesquisa envolvendo seres humanos, tendo sido aprovado pelo Comitê de Ética em Pesquisa da Escola Nacional de Saúde Pública Sergio Arouca, Fundação Oswaldo Cruz, pelo parecer no 1.630.187 de 10 de julho de 2016.

\section{Contexto enunciativo}

É recente a existência da CSIRS na estrutura do Degase, formalizada em 2008, época em que o Departamento passou a ser vinculado à Secretaria de Educação. No fim de 2011, foi realizado um concurso público para 500 vagas de servidores efetivos e quase todos os integrantes das equipes de saúde mental foram admitidos a partir desse ano. Havia cargos específicos para a área de saúde mental, como terapeuta ocupacional e musicoterapeuta 6.

Esses profissionais de saúde mental implantaram em conjunto com a CSIRS uma nova proposta de atenção à saúde mental nas unidades. Antes dessas equipes havia apenas a equipe de medida, responsável pelos relatórios e pareceres usados nas audiências do Judiciário. O foco era o acompanhamento dos processos.

O Degase foi tema de denúncias que destacavam as condições inadequadas de infraestrutura e a superlotação nas unidades 7,8 . Nas duas unidades de internação em que foram realizadas as entrevistas, os profissionais relataram haver mais adolescentes que a quantidade de vagas existentes e mencionaram esta como uma das principais dificuldades para o desenvolvimento do trabalho. Em uma das unidades a equipe estava incompleta. As equipes trabalham 30 horas e os profissionais têm escalas semanais diversas, organizadas internamente em cada unidade.

\section{Resultados e discussão}

\section{Costura frágil: relação das equipes de saúde mental do socioeducativo com a rede de saúde mental}

Do conjunto de enunciações discursivas sobre o tema emerge uma concepção majoritária de que há problemas nas relações entre as equipes das unidades socioeducativas e os serviços de saúde mental, principalmente os CAPS; e entre a CSIRS do Degase e as Secretarias Municipais de Saúde.

A metáfora da "costura" é usada por um dos entrevistados para sintetizar aquilo que é visto como a principal dificuldade: 
[1] "Claro que a gente tem que privilegiar o caso a caso, cada um é um, e isso a gente nunca vai abrir mão. Entretanto, falta ainda uma politica que costure isso tudo. A gente tem a PNAISARI que chegou, mas ela ainda tá (...) engatinhando, né?” (Entrevista 3).

[2] "Então eu acho que esse alinhavo, né?, pra que as coisas sejam mais fluidas...” (Entrevista 3).

O termo "alinhavo" reforça a metáfora da costura para avaliar a gestão e a organização dos serviços de saúde mental e sua relação com as unidades. O sentido é de que as partes não estão devidamente conectadas e não há um alinhamento político que seja suficiente para garantir o acesso dos adolescentes à rede. Ou seja, quando há necessidade de encaminhamento para a rede, as equipes precisam repactuar, reforçar acordos anteriores mal “alinhavados”. Dessa maneira, é como se a cada novo acesso todo o fluxo estivesse sendo novamente pactuado, rediscutido; o que gera dificuldades para as equipes. O termo "fluidas" é usado em um novo sentido para reforçar o desejo de uma ação sem rupturas, que corra sem obstáculos.

A falta de uma "costura" ou de uma "amarração" entre as decisões políticas e as ações cotidianas é vista como uma consequência da não adesão dos municípios à PNAISARI e também como uma ausência de responsabilização dos municípios pela saúde dos adolescentes que cumprem medida. O termo "engatinhando" usado no Trecho 1 em um sentido distinto do literal descreve como está a implantação da PNAISARI e traz a ideia de que as ações necessárias para o alcance dos objetivos apenas foram iniciadas, faltando muito para um cenário desejável e amadurecido.

[3] "Nos outros municípios, assim, a gente consegue pactuar alguma coisa, mas formalizar mesmo, contratar esses profissionais com as equipes de referência, ainda tá muito incipiente” (Entrevista 3).

[4] "Esse entendimento de que o adolescente que está numa unidade socioeducativa ele é usuário daquele serviço também, sabe. Esse entendimento às vezes é difícil...” (Entrevista 3).

Há o recurso da modalidade e de expressões de polidez nessas falas em que os entrevistados criticam a articulação com a rede. "Incipiente", "alguma coisa”, "às vezes” são termos que amenizam o sentido do discurso crítico à baixa implantação das normativas preconizadas na PNAISARI e indicam tolerância cultural entre os hiatos do que é preconizado nos normativos e o que se traduz em ações. Nas falas seguintes de outros entrevistados as críticas aparecem mais diretas, como se fossem "dados" da realidade. [5] "O Rio de Janeiro já disse que não quer" (Entrevista 3).

[6] “...os municípios não querem pactuar com o estado porque está falido e nem vão pactuar com o federal porque o governo federal não vai mais fazer o repasse da PNAISARI” (Entrevista 2).

Nos Trechos 5 e 6 fica claro o posicionamento dos entrevistados sobre a falta de interesse dos municípios em aderir à PNAISARI. Para o Entrevistado 2 isso se deve à falta de recursos financeiros tanto do estado quando do Ministério da Saúde. Os sujeitos dos verbos estão bem definidos e há pressuposições com verbos no indicativo. E a precária "costura” mencionada anteriormente como um problema parece refletir o desinteresse dos responsáveis pelas áreas de saúde dos municípios e do estado, bem como a incapacidade do Ministério em garantir os repasses.

Concepções divergentes foram enunciadas nos depoimentos de dois entrevistados que avaliam a relação com a rede de saúde mental positivamente.

[7] “...eu pouco faço contato com a rede, fica mais a passo de [nome de outro entrevistado] $e$ [nome de outro entrevistado] (...). Mas assim é um contato muito próximo, é um contato que sempre as unidades tão dispostas a tá, é, contribuindo e participando...” (Entrevista 5).

[8] "Todos os meninos que passam pela gente, a gente já tenta fazer esse contato com a rede de saúde mental, né?, com os CAPSi e normalmente a gente tem bons retornos" (Entrevista 6).

Destaca-se no Trecho 7 a contradição dos argumentos, pois o entrevistado diz fazer pouco contato com a rede apesar de considerar o contato próximo, avaliando os serviços como disponíveis. O uso do advérbio "sempre" reforça a avaliação positiva do entrevistado em relação ao contato com a rede que não é feito por ele, mas por outros da equipe.

Já no Trecho 8 as afirmações são menos categóricas e o entrevistado relata que "tenta" fazer contato com a rede e que "normalmente" os resultados são satisfatórios. Tais enunciados poderiam dar a impressão que em uma região do município funciona melhor a articulação entre a unidade socioeducativa e os serviços de saúde mental. Entretanto, esses mesmos entrevistados relatam dificuldades de transporte dos adolescentes, bem como a existência de poucos CAPS que realizam ações dentro das unidades. As falas deixam a impressão de que as solicitações de acesso dos jovens à rede ocorrem em 
raros momentos, mas quando é realizado o contato com o CAPS parece ser possível viabilizar a ida do adolescente ao serviço.

Cavalcanti et al. ${ }^{9}$ ressaltam que é um desafio das políticas sociais a superação da fragmentação das ações. Os autores se referem tanto às dificuldades de interlocução entre setores governamentais distintos, como saúde e justiça, como também entre os órgãos de saúde dos três entes federados. As estruturas de gestão das políticas são particulares e distintas, podendo se tornar fechadas e focadas em seus próprios processos organizativos, dificultando o diálogo e a articulação de uma rede descentralizada. As diferentes agendas políticas dos entes também podem representar um obstáculo.

\section{Precariedades, "resistência de mentalidade" e atendimento incerto após internação: discursos sobre as dificuldades do Degase e dos serviços da rede}

Os enunciados ressaltam uma ênfase discursiva nas dificuldades de infraestrutura, sobretudo a falta de transporte para garantir o acesso dos adolescentes e dos profissionais aos serviços da rede. Os relatos são unânimes em mencionar a pouca quantidade de carros disponíveis e sua utilização prioritária para transportar os adolescentes às audiências.

[9] "É como eu te falei, o nosso grande problema hoje chama-se mobilidade, tanto do adolescente para a rede quanto dos técnicos para a rede" (Entrevista 2).

[10] "Mas, assim, eu já tomei conhecimento de alguns casos de que o adolescente frequentava o CAPS aqui de Madureira e conseguiram pactuar, mas aí era um caso muito específico. Mas não é uma prática, uma rotina daqui, até por conta dessa dificuldade de transporte mesmo..." (Entrevista 4).

[11] "Não temos um carro disponivel. Ou a gente usa nossos recursos, ou quando em último caso a gente consegue o carro da unidade, mas é bem difícil porque é um carro só pra atender tudo" (Entrevista 5).

[12] “... a gente faz esse acompanhamento, é (...) mais via telefone porque a gente quase não tem carro, né?, pra fazer essas idas. Geralmente quando a gente vai, a gente vai por conta própria mesmo, entendeu?" (Entrevista 6).

[13] “...o carro não existe, dai você tem que agendar, daí a Kombi quebra, é uma confusão...” (Entrevista 8).

As orações são construídas no Indicativo, algumas vezes no presente, outras no passado, mas sempre ilustradas com fatos. Ou seja, os enunciados são categóricos ao afirmar que não há carro disponível para transportar os adolescentes para atendimentos externos. Há uso de negações, também nesse mesmo sentido categórico, como "não temos carro disponível". O Trecho 12 é o único em que há o uso de modalizadores como "quase" e "geralmente" para relativizar as afirmações. O uso de "nosso" no Trecho 9 dá a ideia de que a dificuldade com o transporte é compartilhada por todas as unidades.

No Trecho 13 o entrevistado é irônico ao afirmar que o carro "não existe" e depois informar que é necessário "agendar", o que reforça um sentido de contradição entre as orações. Em seguida, o entrevistado relata que o carro "quebra" e caracteriza este processo como uma "confusão". Assim, o carro que está na unidade para transporte dos adolescentes parece não estar disponível para as equipes de saúde, que não podem confiar nele como um recurso acessível quando necessitam.

O discurso acerca das precariedades ganha mais elementos empírico-narrativos com a menção ao baixo quantitativo de agentes socioeducativos. A legislação prevê a possibilidade de saída monitorada para tratamento de saúde 10. Para a viabilização do acesso à rede de saúde é necessário que agentes acompanhem o adolescente. Em três entrevistas há menções ao fato de que as unidades nunca estão com o número adequado de agentes que possibilite o atendimento das solicitações da equipe de saúde mental. [14] "Então se não tem gasolina, com superlotação, os agentes ficam à mercê dos juizes pra fazer o quê?? Audiência! Quem vai levar pra atendimento?” (Entrevista 2).

[15] “...desde que eu comecei a trabalhar aqui sempre tem problema com falta de agente. Assim, a gente nunca trabalhou com um número folgado, assim, de agente que a gente pudesse fazer tudo que a gente precisasse fazer..." (Entrevista 7).

[16] "Pra levar o menino no CAPSi você precisa ter um agente que vai acompanhar, por motivos de segurança. Não tem agente suficiente, tem 400 meninos na unidade, tá o caos..." (Entrevista 8).

Conforme o Trecho 14, a prioridade dos agentes e da instituição é cumprir as determinações judiciais e o transporte é usado, assim, para levar os adolescentes aos locais das audiências. Nesse trecho, a expressão "à mercê" é usada de forma irônica para caracterizar a posição subalterna dos agentes em relação aos juízes, já que os primeiros devem ficar totalmente disponíveis para as solicitações judiciais. 
Cavalcanti et al. 9 também mencionam a forte tendência no socioeducativo em priorizar os trâmites processuais em detrimento das "garantias" sociais, para as quais há um minimalismo.

Os termos "sempre" e "nunca" no Trecho 15 dão a ideia de certeza nas afirmações, bem como de continuidade ao longo do tempo dos problemas. No Trecho 16, o entrevistado descreve a situação como um "caos" e resume em uma palavra a situação da unidade em relação ao transporte. Outras questões estruturais e institucionais estão presentes conforme vistorias realizadas no Degase, tais como violência, isolamento e precária atenção à saúde 8 .

Boas et al. 11 identificam alguns desafios para a assistência e a promoção da saúde do adolescente que cumpre medida de privação de liberdade. Entre eles destacam-se a fragmentação das ações de atendimento e as dificuldades de articulação com a rede de saúde. Fernandes et al. 12 apontam a estigmatização dos adolescentes pelos profissionais de saúde como um problema para a garantia do direito à saúde. Também identificam que os gestores e profissionais de saúde do município e do estado nem sempre se veem como responsáveis pelo atendimento aos adolescentes que estão cumprindo medida socioeducativa em seu território.

Vilas Boas 13 menciona que os profissionais de saúde que fazem os atendimentos aos adolescentes tanto dentro quanto fora das unidades de internação relatam sobrecarga de trabalho e condições precárias.

Além dos enunciados que reconhecem como barreiras a precariedade da infraestrutura, agrega-se outro forte elemento discursivo que um dos entrevistados nomeia de "resistência de mentalidades". Essa forma de nominalização sintetiza de maneira simplificadora as discriminações e os preconceitos tanto do Degase quanto de alguns serviços de saúde mental, os CAPS. Em relação ao Degase, os entrevistados relatam que o acesso à saúde não é visto por alguns profissionais do socioeducativo como um direito do adolescente. Na Entrevista 8 há um recurso de interdiscursividade direta, utilizado para ilustrar e dar fidedignidade quando o entrevistado menciona que a afirmação "Ah, que saúde mental o quê, bandido não tem isso...” já foi ouvida no local em que trabalha.

Em relação aos CAPS, o mesmo entrevistado assume a narrativa biográfica e relata ter encontrado resistência em atender um adolescente que cumpria medida socioeducativa, com o agravante de que o adolescente já era acompanhado pelo CAPSi antes da internação, ou seja, já era um usuário do serviço. [17] "Então eu liguei pro CAPSi (...). Ah, então, ele tá aqui. Como é que a gente faz pra levar ele aî? 'Como assim levar ele aqui? Trazer ele aqui? Ele já não tá aí? E por que é que vocês querem trazer ele aqui?’ ” (Entrevista 8).

Os questionamentos seguidos usados nas orações demonstram a surpresa do entrevistado com a reação do profissional do CAPS. A interdiscursividade evidenciada na reprodução de diálogo pode ser um recurso também didático, com perguntas, respostas e entonações de defesa da interpretação do entrevistado sobre a situação relatada.

O preconceito em relação aos adolescentes que cumprem medida está presente tanto entre os profissionais do sistema de justiça quanto entre os da saúde. Conforme Vicentim \& Gramkow 14, profissionais da rede também precisam trabalhar as suas próprias resistências a fim de romper o distanciamento entre os adolescentes e os serviços, mais recorrente em relação aos adolescentes autores de ato infracional devido ao estigma da periculosidade.

Vilas Boas 13 identifica em uma pesquisa com profissionais de saúde nas unidades básicas que atendem adolescentes que cumprem medida de internação que há muitos relatos sobre a sensação de medo destes profissionais, o que pode acirrar as resistências. A autora aponta que entre as equipes de saúde das unidades socioeducativas, ao contrário, há uma sensação de segurança, principalmente devido à presença dos agentes socioeducativos.

A análise da produção discursiva dos profissionais de saúde mental permite inferir que há um inequívoco reconhecimento das dificuldades para viabilizar o acesso dos adolescentes à rede enquanto cumprem a medida, que a articulação com esta rede é pontual, à distância (por telefone) e com o objetivo de tentar que o adolescente acesse o serviço quando cumprir a medida de internação.

[18] "Quando ele sair a gente encaminha, normalmente é assim que funciona" (Entrevista 8).

[19] "...quando ele tiver perto de sair a gente liga pro CAPS, passa o caso, dá as orientações pro adolescente e pra família e pede pra levar. Dá certo? Dá, às vezes dá, às vezes não dá, mas aí né?, nada garante nada" (Entrevista 8).

A expressão usada pelo entrevistado no final do Trecho 19 "nada garante nada" indica que há descrença e desânimo quanto ao fluxo estabelecido entre a unidade socioeducativa e os serviços de saúde 
mental e quanto ao real início de tratamento no CAPS quando o adolescente sai da unidade. Também indica que não existe um processo de acompanhamento desses adolescentes depois que cumprem a medida e que há um tom de tristeza nos enunciados quanto a isto.

O fragmento discursivo a seguir aponta a sensação de frustração e resume a angústia dos profissionais quando realizam no cotidiano as tentativas de articular o acesso dos adolescentes à rede. $\mathrm{O}$ uso da expressão "cara na porta cem vezes" demonstra o sofrimento dos profissionais quando tentam acionar os CAPS e estes não viabilizam o acesso dos adolescentes.

[20] “... as duas coisas são horriveis - você acreditar e dar com a cara na porta cem vezes e também deixar de acreditar, não sei o que é pior...” (Entrevista 8).

A não adesão do município que tem a quase totalidade das unidades socioeducativas de internação à PNAISARI e a existência de pactos instáveis entre os gestores da saúde e do socioeducativo interferem de maneira significativa nas relações estabelecidas no cotidiano entre os profissionais do sistema socioeducativo e os profissionais dos CAPS.

Conforme previsto na PNAISARI, a equipe de atenção básica de referência para a unidade socioeducativa detém responsabilidade sanitária em relação aos adolescentes e coordena o cuidado nas redes de atenção à saúde 1 . A responsabilidade sanitária não dependeria de adesão formal à PNAISARI, assim como o acesso ao cuidado e à rede de saúde mental. Ao mesmo tempo, de acordo com publicações da área, o CAPSi é o dispositivo para o atendimento dos casos de maior gravidade e responsável por "agenciar e ordenar a demanda" de saúde mental de crianças e adolescentes em um território, abrangendo a articulação para além dos órgãos de saúde 15 . O que se observa nos enunciados dos entrevistados é que nem a atenção básica nem o CAPSi realiza interface com os profissionais das unidades socioeducativas, que acabam atuando de maneira isolada.

Aqui se faz relevante ressaltar a fragilidade dos próprios CAPSi em desempenhar suas funções. Além do baixo investimento financeiro, os CAPSi têm dificuldades como falta de capacitação adequada, número reduzido de profissionais, fragmentação do cuidado, entre outras 16.

Uma questão que aparece nos enunciados é a internação dos adolescentes em entidades religiosas após o cumprimento da medida devido ao uso abusivo de drogas, mediante solicitação da família.

[21] "Se eu tenho um menino que ele não tá em sofrimento psíquico agudo, mas ele tem comportamento compulsivo relacionado às drogas, que a família não dá conta, aí ele [Judiciário] quer internar" (Entrevista 2).

O que se percebe é a tutela dos adolescentes por uma nova instituição vista como estratégia para protegê-los. É histórica no Brasil a institucionalização de adolescentes e a concepção do Estado como ente tutelar desta população. Um dos desafios da Reforma Psiquiátrica no campo da saúde mental infantojuvenil é superar a desassistência e a ausência de cuidado características das ações segregadoras e totalizantes direcionadas a este público, focadas em retirá-los do convívio comunitário 17.

\section{Perspectivas e propostas}

Entre os enunciados dos profissionais sobre o trabalho que realizam e sua articulação no cotidiano com os CAPS, há uma variedade de conclusões e perspectivas futuras apontadas.

[22] “...o olhar não pode ser que todo esse atendimento tem que ser externo, isso não (...). Hoje se o meu atendimento é externo eu tô frito!" (Entrevista 2).

No Trecho 22, observa-se o uso de duas negações seguidas, o segundo "não" para reforçar a posição do entrevistado de que o atendimento aos adolescentes precisa ser feito também dentro das unidades socioeducativas e não apenas na rede. A expressão "eu tô frito" resgata uma linguagem coloquial para expressar a opinião do entrevistado que vai ao encontro do que é preconizado na PNAISARI e em outros documentos divulgados pelo Ministério da Saúde 1,18.

[23] “...desde que eu cheguei, pra mim é claríssima a necessidade de ter uma supervisão, sabe assim, alguém que venha dar supervisão para a equipe (...). Esse trabalho de ter alguém de fora que não tá envolvido diretamente...” (Entrevista 8).

Esse entrevistado deixa claro que é o sujeito da proposta apresentada, já que usa o pronome "eu" e a expressão "pra mim" logo em seguida. Enfatiza sua ideia com o uso de superlativo no termo "claríssima". O uso dessa expressão torna a afirmação categórica. O termo "de fora" enfatiza a expectativa que o profissional responsável pela supervisão seja alguém que não vivencie o cotidiano do Degase e suas lógicas institucionais. 
[24] “...faz toda diferença você ter uma política de relações que funcione, né?, se aproximar, se apresentar, criar boas relações com esses profissionais..." (Entrevista 8).

[25] "É, eu acho que tem certas vezes dificuldade da gente se reunir um pouco em equipe (...), até com os equipamentos fora também, né?...” (Entrevista 6).

No Trecho 24, o entrevistado propõe uma "política de relações” com os profissionais da rede de saúde mental como estratégia para reduzir as resistências. No Trecho 25, outro entrevistado menciona a dificuldade em realizar reuniões com a equipe da unidade e com as equipes dos serviços. $\mathrm{O}$ tom dos enunciados é distinto, apesar de tratarem de temas semelhantes. "Boas relações” remete à política da boa vizinhança. No segundo trecho a ideia é realizar reuniões de equipe. Nesse caso, o entrevistado usa de modalidade - "certas vezes", "um pouco" - dando a ideia de que existem tentativas de realizar reuniões, mas raramente ocorrem. A expressão "até com" demonstra a dificuldade aparente em se aproximar dos profissionais dos CAPS, como se fosse algo possível, mas distante da realidade.

Barbosa et al. 19 identificam o trabalho em equipe como uma das principais características do CAPS. Também apontam a supervisão clínica-institucional como estratégia para a saúde da equipe, possibilitando "extrapolar o lugar solitário de especialista". Assim, o modo proposto de funcionamento dos serviços de saúde mental no território parece ser usado como referência também pelos profissionais que estão nas equipes do sistema socioeducativo, tanto para analisarem e refletirem sobre o próprio trabalho quanto para pensar possibilidades de melhoria.

[26] "O serviço que tem no socioeducativo tem que ser reconhecido na RAPS. (...) não tem como não ser reconhecido, ele é um ponto de apoio da rede” (Entrevista 2).

Nessa citação o entrevistado dá um tom de inquestionabilidade com o uso da expressão "tem que ser" e com a repetição do "não", reforçando a afirmação feita anteriormente. Os verbos estão no presente do Indicativo e também contribuem para essa intenção. O entrevistado faz uma referência indireta à PNAISARI que preconiza que os profissionais de saúde das unidades socioeducativas devem ser registrados no Cadastro Nacional de Estabelecimentos de Saúde (CNES) 20. Todos os profissionais de saúde da unidade são cadastrados como "atenção básica”, incluindo aqueles de saúde mental. Em vários momentos da Entrevista 2 é mencionado que a atenção básica no sistema socioeducativo é reconhecida pelo Sistema Único de Saúde (SUS) como um serviço de saúde, entretanto, o mesmo não ocorreria para a saúde mental. Como já apontado, a PNAISARI apresenta uma perspectiva distinta, com a diretriz de que existem matriciadores na atenção básica para a viabilização do acesso ao cuidado em saúde mental fora das unidades.

\section{Considerações finais}

As políticas de saúde têm como desafios superar as desigualdades entre necessidades e ofertas nos territórios, além de efetuar articulação intersetorial para ações que envolvam áreas além do setor saúde. São atingidas recorrentemente por propostas conservadoras de reforma e redução do Estado. Tais desafios são comuns a outras políticas sociais e impactam na continuidade e institucionalidade das ações implantadas 21. A fragilidade do atendimento aos adolescentes que cumprem medida é um reflexo também desse contexto geral e se verifica não apenas no Rio de Janeiro, mas também em outros locais.

Entre as diretrizes da PNAISARI destaca-se a incompletude institucional das unidades socioeducativas. Preconiza-se que as unidades sejam abertas à comunidade em que se inserem e à organização territorial da assistência à saúde. É relevante o acesso a múltiplas instituições e ações desenvolvidas por instâncias distintas e comunitárias 1 .

Outro aspecto da política nacional é o reforço do papel dos municípios como responsáveis sanitários por esses adolescentes. Todavia, distanciando-se da lógica normativa, indo ao cotidiano das instituições, as relações entre os órgãos gestores das medidas socioeducativas de privação de liberdade (vinculados aos estados) e as Secretarias de Saúde municipais são marcadas por conflitos e dificuldades.

A não adesão à PNAISARI sinaliza falta de engajamento dos gestores locais na implantação da política pactuada nacionalmente, o que impacta na rotina das equipes dos serviços de saúde que representam o primeiro nível de articulação com as unidades socioeducativas. Há maior "fluidez" e 
fragilidade das pactuações, não respaldadas por uma política institucionalizada e com alta dependência da orientação política dos gestores estratégicos do momento.

Cabe às Secretarias de Saúde a responsabilidade pela incorporação dos adolescentes em privação de liberdade na população de abrangência dos serviços territoriais, de tal maneira que contribuam para a garantia do direito desses jovens ao acesso à saúde em todos os níveis de complexidade, o que inclui a saúde mental. Sem o protagonismo das diversas áreas e instituições não é possível a inclusão dos adolescentes nas políticas públicas conforme preconizado pelo sistema de garantia de direitos.

Os enunciados privilegiam os CAPS como interlocutores preferenciais dos profissionais de saúde mental das unidades, e outros pontos da RAPS não são destacados. Destacamos a ausência da atenção básica, que seria uma ponte entre as unidades socioeducativas e as redes de atenção à saúde. Os profissionais de saúde mental mencionaram que não faz parte do cotidiano o contato com a atenção básica do território. Entre os entrevistados das unidades socioeducativas, a CSIRS do Degase também não é enfatizada como parceira na interlocução cotidiana com a RAPS.

Os discursos convergem no que se refere aos problemas estruturais do sistema socioeducativo, que são constituídos como barreiras ao acesso à rede de saúde mental por intermédio dos CAPS. Há ambiguidades nos enunciados de reflexão sobre a relação com os CAPS - ora são destacadas as resistências pessoais dos profissionais das unidades e da rede, ora os serviços são vistos como disponíveis quando acionados. As perspectivas e as propostas elencadas apontam para caminhos divergentes - ora enfatizam a necessidade de melhoria e de fortalecimento da articulação com a rede territorial externa, ora o foco se volta ao esforço de reconhecer as equipes internas de saúde mental como extensão da rede enquanto pontos de atenção dentro das unidades. Nesse sentido, o que há de comum é a concepção de que a integração com a RAPS é uma necessidade, mesmo que a assistência seja realizada nas unidades socioeducativas.

Raramente ocorre o acesso dos adolescentes a serviços de saúde externos à unidade; alguns profissionais disseram que nunca viram isto acontecer, apenas "ouviram falar" que ocorreu no passado. Nesse sentido, a acessibilidade como premissa na saúde mental é prejudicada, pois abrangeria superar a segregação e o isolamento incorporando na lógica de atuação a diversificação de ofertas de maneira integrada e para além do setor saúde 22 . Os enunciados apontam para o isolamento tanto dos adolescentes quanto dos profissionais em relação às ações e políticas de saúde mental do território.

\section{Colaboradores}

Todos os autores contribuíram igualmente para a elaboração do artigo.

\section{Agradecimentos}

Ao Departamento Geral de Ações Socioeducativas (Degase), que autorizou a realização da pesquisa nas unidades socioeducativas e aos profissionais entrevistados.

\section{Referências}

1. Ministério da Saúde. Portaria no 1.082, de 23 de maio de 2014. Redefine as diretrizes da Política Nacional de Atenção Integral à Saúde de Adolescentes em Conflito com a Lei, em Regime de Internação e Internação Provisória (PNAISARI), incluindo-se o cumprimento de medida socioeducativa em meio aberto e fechado; e estabelece novos critérios e fluxos para adesão e operacionalização da atenção integral à saúde de adolescentes em situação de privação de liberdade, em unidades de internação, de internação provisória e de semiliberdade. Diário Oficial da União 2014; 24 mai.

2. Ministério da Saúde. Portaria no 3.088, de 23 de dezembro de 2011. Institui a Rede de Atenção Psicossocial para pessoas com sofrimento ou transtorno mental e com necessidades decorrentes do uso de crack, álcool e outras drogas, no âmbito do Sistema Único de Saúde (SUS). Diário Oficial da União 2011; 26 dez. 
3. Lykouropoulos CB, Péchy SHS. O que é um CAPSi? In: Lauridsen-Ribeiro E, Lykouropoulos CB, organizadores. O Capsi e o desafio da gestão em rede. São Paulo: Editora Hucitec; 2016. p. 87-99.

4. Prefeitura do Rio de Janeiro. Centro de Atenção Psicossocial (CAPS). http://www.rio. rj.gov.br/web/sms/caps (acessado em 18/ Ago/2017).

5. Fairclough N. Discurso e mudança social. Brasília: Editora UnB; 2001.

6. Lopes ERC. A política socioeducativa e o DEGASE no Rio de Janeiro: transição de paradigma? Jundiaí: Paço Editorial; 2015.

7. Unidades do Degase no RJ têm superlotação, doenças e mofo. http://g1.globo.com/rio-dejaneiro/noticia/2016/09/unidades-do-degaseno-rj-tem-superlotacao-doencas-e-mofo.html (acessado em 28/Set/2016).

8. Conselho Federal de Psicologia; Conselhos Regionais de Psicologia; Conselho Federal da Ordem dos Advogados do Brasil. Direitos Humanos: um retrato das unidades de internação de adolescentes em conflito com a lei. 2a Ed. http://site.cfp.org.br/wp-content/ uploads/2006/08/Direitos_Humanos_um_ retrato_das_unidades_de_internacao_de_ adolescentes_em_conflito_com_a_lei.pdf.

9. Cavalcanti PB, Dantas ACS, Carvalho RN. Contornos e sinergias entre a política de saúde e o adolescente privado de liberdade: intersetorialidade como desafio. Textos Contextos (Porto Alegre) 2011; 10:399-410.

10. Brasil. Lei no 12.594. de 18 de janeiro de 2012. Institui o Sistema Nacional de Atendimento Socioeducativo (Sinase), regulamenta a execução das medidas socioeducativas destinadas a adolescente que pratique ato infracional; e altera as Leis no 8.069, de 13 de julho de 1990 (Estatuto da Criança e do Adolescente); 7.560, de 19 de dezembro de 1986, 7.998, de 11 de janeiro de 1990, 5.537, de 21 de novembro de $1968,8.315$, de 23 de dezembro de 1991 , 8.706, de 14 de setembro de 1993, os Decretos -Leis no 4.048, de 22 de janeiro de 1942, 8.621, de 10 de janeiro de 1946, e a Consolidação das Leis do Trabalho (CLT), aprovada pelo Decreto-Lei no 5.452, de 1o de maio de 1943. Diário Oficial da União 2012; 19 jan.

11. Boas C, Cunha C, Carvalho R. Por uma política efetiva de atenção integral à saúde do adolescente em conflito com a lei privado de liberdade. Rev Méd Minas Gerais 2010; 20:225-33.

12. Fernandes FMB, Ribeiro JM, Moreira MR. A saúde do adolescente privado de liberdade: um olhar sobre políticas, legislações, normatizações e seus efeitos na atuação institucional. Saúde Debate 2015; 39(spe):120-31.

13. Vilas Boas CC. A atenção à saúde do adolescente privado de liberdade em Belo Horizonte: impasses e desafios [Tese de Doutorado]. Belo Horizonte: Universidade Federal de Minas Gerais; 2014.
14. Vicentim MCG, Grawkow G. Que desafios os adolescentes autores de ato infracional colocam ao SUS? Algumas notas para pensar as relações entre saúde mental, justiça e juventude. In: Lauridsen-Ribeiro E, Tanaka OY, organizadores. Atenção em saúde mental para crianças e adolescentes no SUS. São Paulo: Editora Hucitec; 2010. p. 337-51.

15. Couto MCV, Delgado PGG. Presença viva da saúde mental no território: construção da rede pública ampliada de atenção para crianças e adolescentes. In: Lauridsen-Ribeiro E, Lykouropoulos CB, organizadores. O Capsi e o desafio da gestão em rede. São Paulo: Editora Hucitec; 2016. p. 161-92.

16. Delfini PSS, Reis AOA. Articulação entre serviços públicos de saúde nos cuidados voltados à saúde mental infanto-juvenil. Cad Saúde Pública 2012; 28:357-66.

17. Couto MCV, Delgado PGG. Crianças e adolescentes na agenda política da saúde mental brasileira: inclusão tardia, desafios atuais. Psicol Clín 2015; 27:17-40.

18. Assis DAD, Barreto C. Saúde mental na infância e adolescência: atenção psicossocial e o Sistema Nacional de Atendimento Socioeducativo (SINASE). Florianópolis: Universidade Federal de Santa Catarina; 2014.

19. Barbosa CL, Lykouropoulos CB, Mattos MM, Ventura MF, Siebert M. O desafio cotidiano de ser equipe em um CAPSi. In: Lauridsen-Ribeiro E, Lykouropoulos CB, organizadores. O Capsi e o desafio da gestão em rede. São Paulo: Editora Hucitec; 2016. p. 102-8.

20. Ministério da Saúde. Portaria no 973, de 29 de setembro de 2014. Estabelece normas para o cadastramento no SCNES das equipes e serviços que farão parte da Política Nacional de Atenção Integral à Saúde de Adolescentes em Conflito com a Lei (PNAISARI). Diário Oficial da União 2014; 30 set.

21. Noronha JC, Lima LD, Machado, CV. O Sistema Único de Saúde - SUS. In: Giovanella L, Escorel S, Lobato LVC, Noronha JC, Carvalho AI, organizadores. Políticas e sistema de saúde no Brasil. 2a Ed. Rio de Janeiro: Editora Fiocruz; 2012. p. 435-72.

22. Alves DS. Integralidade nas políticas de saúde mental. In: Pinheiro R, Mattos RA, organizadores. Os sentidos da integralidade na atenção e no cuidado à saúde. 8a Ed. Rio de Janeiro: Centro de Estudos e Pesquisa em Saúde Coletiva, Instituto de Medicina Social, Universidade do Estado do Rio de Janeiro/Associação Brasileira de Saúde Coletiva; 2009. p. 167-76. 


\section{Abstract}

The aim of this article is to analyze how professionals in the mental health teams of the juvenile detention system in Rio de Janeiro, Brazil, perceive the relations with the external Network of Psychosocial Care in dealing with mental health issues in adolescents serving time in juvenile detention centers. Nine interviews were held with mental health professionals in the system, and the results were presented with Fairclough's critical discourse analysis as the reference. The results were organized in three parts: the relationship between the juvenile detention system's mental health teams and the external services, difficulties experienced by the teams from the detention centers and the external network's services, and prospects and proposals. The logic of the arguments' development showed that the weakness in the agreements between administrators of the Brazilian Unified National Health System and the juvenile detention system has a daily impact on mental health activities conducted by the centers' teams. This scenario is aggravated by other structural problems such as lack of transportation and personnel to accompany adolescents on extramural appointments, and resistance on the part of professionals both inside and outside the detention centers. The study showed that both the adolescents and professionals were isolated in relation to mental health activities and policies.

Mental Health; Mental Health Services; Institutionalized Adolescent

\section{Resumen}

Este artículo tiene como objetivo analizar de qué forma los profesionales de los equipos de salud mental del sistema de reinserción socioeducativo de Río de Janeiro, Brasil, perciben las relaciones establecidas con la Red de Atención Psicosocial, para la atención a cuestiones de salud mental de adolescentes que cuentan con medidas de internamiento. Se realizaron nueve entrevistas con profesionales de salud mental del sistema y los resultados se presentaron teniendo como referencia el análisis de discurso crítico de Fairclough. Los resultados se organizaron en tres partes: relación entre los equipos de salud mental y la red, dificultades de los equipos de las unidades y de los servicios de la red, además de perspectivas y propuestas. Por la lógica de construcción de los argumentos identificados se percibió que la fragilidad de los pactos entre los gestores del Sistema Único de Salud y del sistema socioeducativo impacta en el día a día de las acciones en salud mental, desarrolladas por los equipos de las unidades. Este escenario se asocia a otros problemas estructurales, como la falta de transporte y la indisponibilidad de agentes para acompañar a los adolescentes a las consultas externas, así como las resistencias de los profesionales, tanto dentro como fuera de las unidades. Se evidencia que existe un aislamiento, tanto por parte de los adolescentes, como de los profesionales, respecto a las acciones y politicas de salud mental en el territorio.

Salud Mental; Servicios de Salud Mental; Adolescente Institucionalizado
Recebido em 20/Mar/2017

Versão final reapresentada em 18/Ago/2017

Aprovado em 02/Out/2017 